\title{
SIMULATION SERVICES FOR TRAINING OF PLANT OPERATORS
}

\author{
Gerhard Schreck \\ Fraunhofer IPK \\ Pascalstraße 8-9 \\ 10587 Berlin, Germany \\ Gerhard.Schreck@ipk.fhg.de
}

\begin{abstract}
This paper presents an approach for machinery and equipment manufacturers to provide qualification services as value-added-services to its customers. A concept for the provision of a virtual training center by cost-effective simulation services via Internet is outlined. The concept has been developed within a project of the Fraunhofer Association e-Industrial Services. Aspects of simulation service implementation and application are illustrated by a realized system demonstrator for the training of operators of water treatment plants.
\end{abstract}

\section{INTRODUCTION}

Recently, production systems tend to have shorter life cycles, an increased diversity of variants as well as increased complexity. This development also requires innovations for the training of personnel. Qualification is becoming a competitive factor for producers of production systems, who want to guarantee increased availability and a more efficient operation.

A qualified personnel is an essential prerequisite for the safe and effective utilization of production systems. By applying new mediums and electronic work tools, it is possible to extract the fundamental aspects from the, up until now, rigid learning context of operator training and to flexibly arrange the training in terms of time, duration and place (Qualification on demand). Didactically, this opens up new perspectives since such a learning process is, to a great degree, carried out actively as well as interactively.

Within the framework of the Fraunhofer Association e-Industrial Services, adaptive qualification services are being developed for operation, maintenance and service personnel. Innovative and customer-specific training courses and systems can be provided over network portals. A main focus of development at Fraunhofer IPK is the planning and design of qualification services for operator personnel, especially the implementation of simulation-based training systems for system operators (Bernhardt, 2001). 


\section{TRAINING OF PLANT OPERATORS}

\subsection{Developments towards e-Learning}

As working systems become more complex, they require higher qualifications of the work personnel. Due to the increasing degree of automation, the workers are becoming more and more removed from the actual process. Increasingly, the production takes place under the control of a central system which results in fewer workers who operate and supervise systems that are constantly becoming more complex. Especially in highly automated systems, the operator's tasks are limited to making sure that a system runs its course smoothly. However, it is necessary that the operator has the capability to manually operate the process control in case of a disturbance. Accordingly, the standards for the operator's qualification, knowledge and skills become greater.

Computer-based Training (CBT), Distance Learning, WEB-based Training, etc. are the current keywords in connection with the new IT-based educational and training concepts. For this, the internet plays an increasingly important role as the standard platform for the providing and calling up of training programs. In the following text, qualification services that are offered on the internet will be referred to as e-Learning.

For the broad market of EDP-standard products (word processing, spread-sheet calculations, etc.) there is already a wide-array of e-Learning course modules offered. Even the major manufacturers of automation components and systems are beginning to organize training for their products on the internet. Such offers, however, are concentrated on individual components or systems (ex. PLC system) and not on entire customer-specific solutions which are usually implemented in the plant engineering and construction as an individual system. The system operator's training is normally carried out by the manufacturer, on-location, during the line-up and start-up phase of the production system.

However, an effective use of the system resources and the guarantee of a safe and reliable operation require qualification measures and services, which would accompany the entire life-cycle of the system. The previously described marginal conditions have supported the employment of online and simulation-based training systems especially in the applications of process engineering (Winter, 2001). The further application of this approach to production systems in general, alongside economical solutions for the implementation of e-Learning services, has very high potential.

\subsection{Simulators for the Training of Plant Operators}

Training simulators have already been successfully applied for many years to specific industries, such as power stations or large-scale installations of the chemical industry. They represent an important tool for a danger-free and efficient training of the operation personnel. Qualification goals for the use of training simulators are:

- Training of control system operation,

- Training of the initial operation,

- Training of the normal operation,

- Training of the start-up and shut-down procedure, 
- Training of exceptional situations,

- Development of execution alternatives,

- Operator support of the operation.

Training simulators enable the training at a real control system albeit in a virtual set-up, i.e. in a simulated system (virtual plant). Through this set-up, work procedures for the normal operation can be practiced as well as rarely occurring work processes, such as start-up and shut-down of plant operation. Additionally, a danger-free training of how to handle usually very risky disturbances (i.e. system breakdown) as well as the necessary measures to be taken by the operator can be executed. Due to costs, the use of training simulators takes places nowadays almost exclusively in processes and systems that are multiply constructed in the same or similar form.

Training simulators are complex systems which require specially trained technicians for its operation. This includes, for example, a system manager for the maintenance of hardware and system software, at least one instructor as well as a process engineer, who has a strong knowledge on process modeling and knows how to handle the engineering tools in order to update the system. Only with such a simulator-operation personnel is the system capable of being fully employed (NAMUR, 1995). Because of this, training simulators are usually operated in training centers and are sought out by plant operator in scheduled courses (Figure 1).

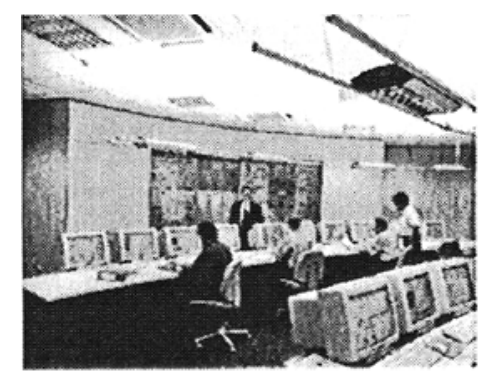

Figure 1 - Training Center for Power Plant Operator

(SimPower Simulator Systems GmbH)

\section{SIMULATION SERVICES FOR TRAINING}

\subsection{Simulation-Based Qualification Services via Internet}

High costs for simulator development, as well as for its on-site operation within central training centers, are a barrier for the widespread application of training simulators in production plants in general. Solutions are required, which enable a cost-efficient provision and application of simulation based qualification services for plant operators.

A concept for the provision of a virtual training center by cost-effective simulation services via Internet has been developed within the project e-Industrial services (Hohwieler, 2001). It is based on a client-server architecture, where the training simulator is located at the site of a service provider, e.g. the machinery and 
equipment manufacturer. The service provider maintains the underlying simulation models of the plant, as well as data bases containing training exercises and profiles of system usage. The operator has access to the training services via an Internet browser. Exercises are offered with reference to his personal qualification profile and training state. Training sessions can be executed self-contained by the operator or, on requested, by support of an human instructor (Figure 2).

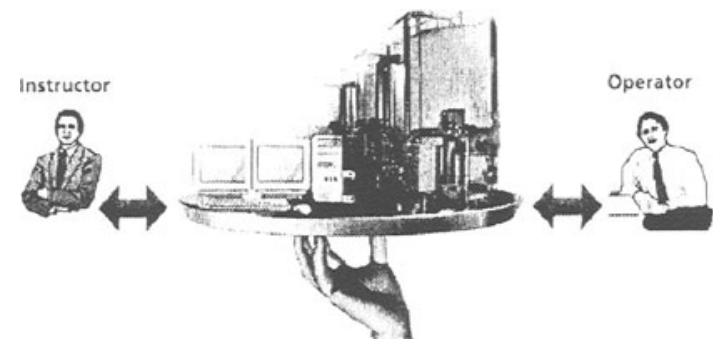

Figure 2 - Access to a Virtual Training Center via the e-IS Service-platform

\subsection{Qualification Services as Value-Added-Services of Machinery and Equipment Manufacturers}

If the system manufacturer is included in the development, or even the operation, of the qualification services, then the greatest synergy occurs in the aforementioned eLearning concept. Through the project phases of planning, implementation and lineup of the system, the system manufacturer has the necessary information and models of the customers system. Furthermore, by making this service continuously available, the underlying information model is subjected to adjustments and improvements. This is the basis for a close co-operation between manufacturer and customer, even during the operation phase, and increases customer relation.

The system manufacturer receives valuable information about the application and operation of his product. Through the evaluation of available operational data, it is possible to identify and analyze the user's problems with the system. From this, both specific training courses and training modules can be derived and concrete suggestions for product improvements are generated (Figure 3).

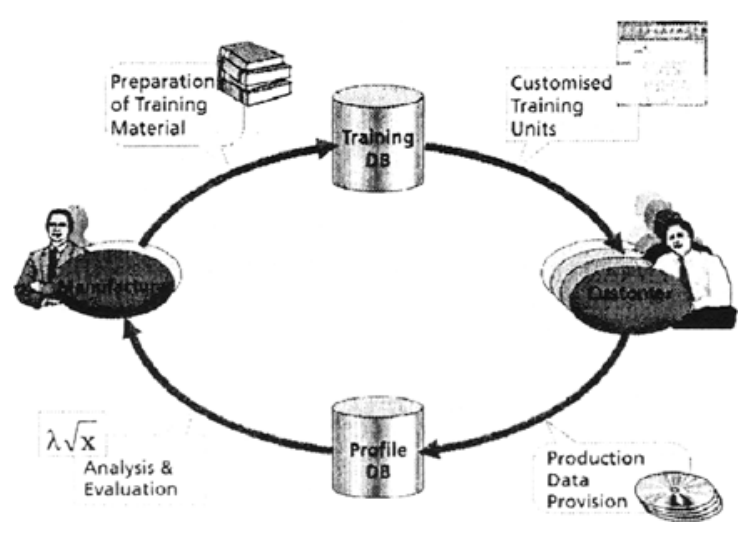

Figure 3 - Manufacturer - Customer Relation 
By such an approach, machinery and equipment manufacturers are able to provide qualification services for the complete product life cycle. In this way, the system manufacturer can provide a variety of new services for operator qualification for his implemented system:

- basic education about the product (before the system's delivery),

- system and process related training course,

- specific re-training when the system has been modified.

\section{PLATFORM CONCEPT FOR E-INDUSTRIAL SERVICES}

With its service platform, the Fraunhofer Association e-Industrial services has created a portal, which will allow both the ordering and execution of e-Services through the Internet. The architecture of the service platform is based on a scalable business model in which the roles of the participants are defined. The model distinguishes between customers, users, retailers and service providers.

The platform includes an application server to authenticate users. The authentication data is sent via an SSL-protected http connection to the application server before being handed over to the service platform using CORBA. Then, the service platform checks the user database to verify the authentication data. The authentication server provides a list of services available to the user and, if applicable, previously interrupted service sessions. Once the user has selected a service, the platform activates the relevant application logic and produces the proper graphic user interface. The user employs this interface to interact with the application logic, which in turn uses other components of the service platform (Figure 4).

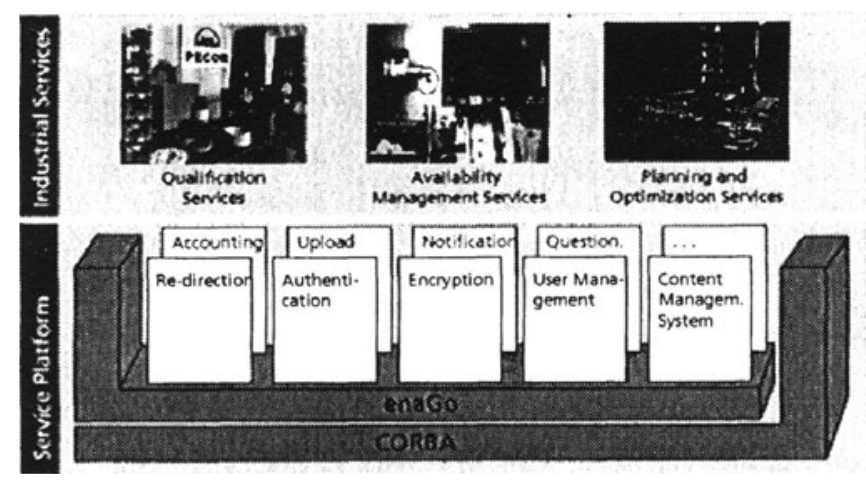

Figure 4 - Service Platform for Implementation and Execution of e-Services

The electronic services integrated in the service platform are offered over an Internet portal operating in a distributed environment. Accordingly, the system architecture makes a clear distinction between application logic and user interface. The application logic is part of the service provider's computer system, whereas the user interface appears on the user's workstations. In order to make the usage of the service as easy as possible while simultaneously enabling the greatest possible 
platform independence, the service platform relies solely on HTML applications. Only services requiring a great deal of interactivity, such as data evaluation or online simulation, are handled through applets or even browser-external applications.

\section{APPLICATION EXAMPLE}

\subsection{Training Operators of Water Treatment Plants}

As an example, the previously described e-Learning concept of the simulation-based training was implemented, in cooperation with an automation supplier, for the operation personnel of water treatment plants. Modern water treatment plants are equipped with control technology which allows a safe operation and a continuous monitoring. The pre-set values of the process technician determine the system's operating points which will afterwards be maintained by the supervisory control system. The selection of operating points is dependent on the know-how of the technician. For this, objective criteria of system management (i.e. specific energy consumption, frequency of change-over processes, planning of cleaning procedures and maintenance work) are only rarely taken into consideration.

The main objective of the process management consists of ensuring a proper operation of the system. For this, the following criteria must be fulfilled:

- Allocation of the required quantity of pure water,

- Consideration of the different modes of working and use of resources,

- Compliance with requirements for the quality of water,

- Adherence to a minimal consumption of energy,

- Maintenance of the purification cycle of individual filters,

- A continuous and smooth running of the system,

- Adherence to the prescribed limits of the tanks with a quick reaction to deviations.

Energy tariffs and prognosis of water decline over a given time period (ex. 24 hours) are marginal conditions of the process management which have to be taken into consideration. Such demanding tasks of process management require the appropriate experience of the operator (Lisounkin, 1999).

Through the implementation of the training simulator, it was possible to set up available models of the system with fundamental simulation components. They were supplied for the necessary functions of training purposes and integrated into the service platform. The use of the individual training modules were organized and managed by a training database.

Figure 5 shows the plant operator's control panel. The individual display and operation elements represent those of the real system. The dynamic reaction to the operators entries, however, are realized by the simulator, which is connected to the internet. Besides using the online simulator for the training of operation personnel, the system operator can also use it for trying out alternative ways of running the system. 


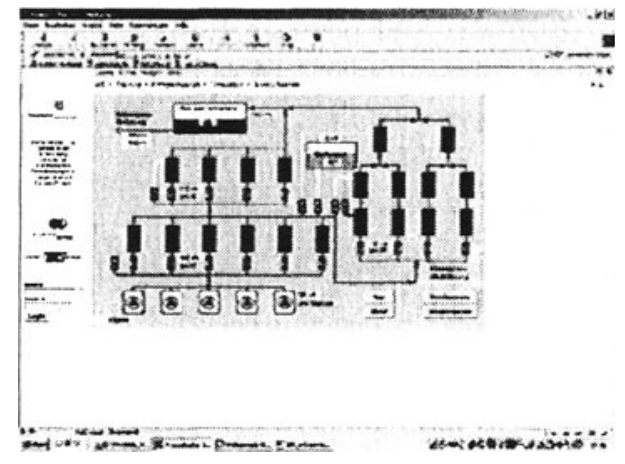

Figure 5 - Example of an Operator Control Panel Screen

\subsection{Adaptation of Training Contents to the User's Needs}

In order to control and document the dynamic course of events within the water treatment plant, the relevant variables of state are recorded in data archives. This information represents a profile of the system's running and will be used for analysis and assessment. It is possible to evaluate the profile of the training exercise as well as the profile of the actual running of the system. From this, training elements can be constructed that coordinate with specific system situations with the training phase of the operator (adaptive).

In Figure 6, there is an example of plant operation profiles, which shows the relation between water consumption, execution of purification cycles, and water production. When optimizing the operation of the system the scheduling of the purification cycles plays an important role for saving energy costs. Such aspects of operation can be very well trained by simulation exercises and analysis of the used plant operation profiles (Lisounkin, 2002)

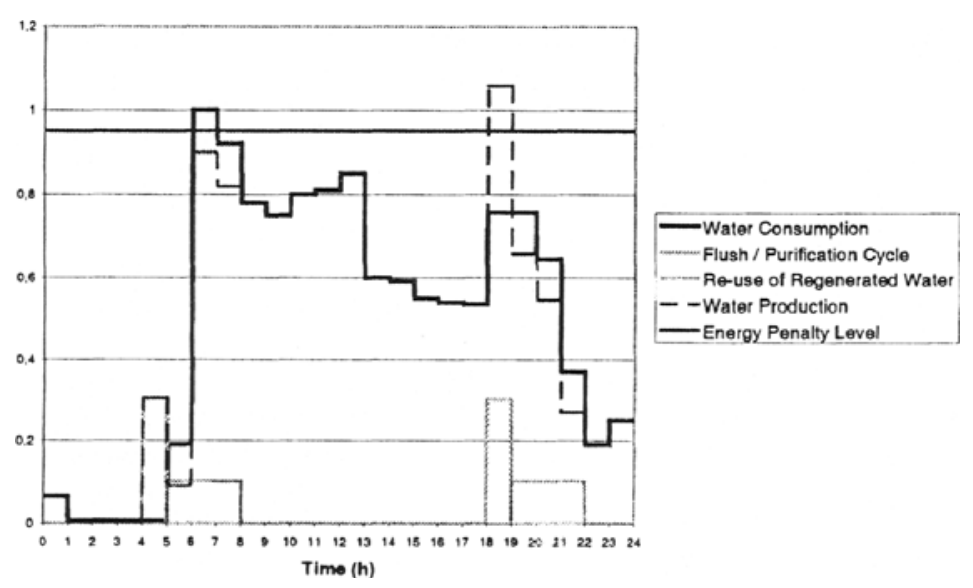

Figure 6 - Example of Plant Operation Profiles 


\section{CONCLUSIONS AND OUTLOOK}

Both manufacturer and user profit from the application of simulation based qualification services through the following advantages:

- Higher availability and optimal use of production systems due to a qualified and trained personnel,

- More effective training through programs that are specifically adjusted to the system and user,

- World wide availability and application possibilities from innovative educational and training programs,

- Possibilities for team training, even when the systems are in different locations.

Within the framework of the developmental environment of the Fraunhofer Association e-Industrial Services, there is a suitable platform for an efficient realization of qualification services via Internet. The prototype training simulator for the operators of water distribution systems serves as a reference point. The available communication and management functions for the handling of services as well as the database structure and models for e-Learning are application-independent and therefore are available for the use of further applications. Plans for the next application include the integration of information modules for qualification of machine tool operators at the shop floor. Further application scenarios will be implemented in cooperation with machine and system producers in order to enable them to offer their customers innovative educational and training services.

\section{ACKNOWLEDGMENTS}

The basic e-Service infrastructure has been implemented by the partners of the Fraunhofer Association e-Industrial services (Fraunhofer e-IS, 2002). Simulation based qualification services are developments of Fraunhofer IPK. We thank our launching customer Elpro Prozessindustrie und Energieanlagen $\mathrm{GmbH}$, Berlin, for the close co-operation and support in the development of the demonstrator system.

\section{REFERENCES}

1. Bernhard R, Schreck G. "Teletraining - Simulationsbasierte Schulung von Bedienpersonal". In Futur 1/2001, 12-13.

2. Winter H, Schmidt, F. "Online-Trainingssystem für Bedienerschulung in Unternehmen der verfahrenstechnischen Industrie”. Duisseldorf: VDI Verlag, 2001 (VDI-Berichte; 1608), S. 457 - 467.

3. NAMUR. "Management von Trainingssimulatorprojekten". NAMUR-Arbeitsblatt NA 60, Version 22.11.95.

4. Hohwieler E, Schreck G, Berger R. "Bereitstellung elektronischer Dienstleistungen für Produktionssysteme". In Proceedings of X. Internationales Produktionstechnisches Kolloquium PTK, Berlin, 27.-28. September 2001, 107-112.

5. Lisounkin A, Schmidt H.-W. "Modellbasierte Prozessführung in einem Wasserwerk". In Journal Wasser und Boden. Vol. 51, 11, 1999, 44-47.

6. Lisounkin A, Schreck G. "Water Consumption Profile Analysis for Facility Control and Operator Training". To be published in Proceedings of ASM 2002, June 25-28, 2002, Crete, Greece.

7. Fraunhofer e-IS. /www.e-industrial-services.de/ 